\title{
Tea polyphenols inactivate Cronobacter sakazakii isolated from powdered infant formula
}

\author{
R. Li, ${ }^{* 1}$ P. Fei, ${ }^{* 1}$ C. X. Man, †‡ B. B. Lou, ${ }^{*}$ J. T. Niu, ${ }^{*}$ J. Feng, ${ }^{*}$ L. H. Sun, ${ }^{*}$ M. Y. Li, ${ }^{*}$ and Y. J. Jiang ${ }^{*} \dagger \ddagger^{2}$ \\ ${ }^{*}$ Key Laboratory of Dairy Science, Ministry of Education, Department of Food Science, Northeast Agricultural University, Harbin 150030 , China \\ †National Research Center of Dairy Engineering and Technology, Northeast Agricultural University, Harbin 150086, China \\ ‡Synergetic Innovation Center of Food Safety and Nutrition, Northeast Agricultural University, Harbin 150030, China
}

\section{ABSTRACT}

This study evaluated the antimicrobial activity of tea polyphenols (TP) against 4 Cronobacter sakazakii strains with different sequence types (ST) isolated from powdered infant formula (PIF). The results showed that in normal saline, $5 \mathrm{mg} / \mathrm{mL}$ of TP $(\mathrm{pH} 3.44)$ could eliminate approximately $7.0 \mathrm{log} \mathrm{cfu} / \mathrm{mL}$ of $C$. sakazakii within $1 \mathrm{~h}$; in rehydrated PIF, after acidification with $\mathrm{HCl}(\mathrm{pH} 3.55)$, TP showed a stronger antibacterial activity compared with the controls (malic acid, ascorbic acid, and citric acid). Further, some differences were obvious in tolerance to TP between C. sakazakii strains with different ST. The tolerance of C. sakazakii CE1 (ST4) to TP was found to be greater than that of the other 3 C. sakazakii strains (ST1, ST8, and ST64). The results of recovered test and transmission electron microscope analysis revealed that the action of TP against C. sakazakii was an irreversible bactericidal process caused by leakage of cytoplasm. Taken together, these results indicated that TP had an effective bactericidal effect against C. sakazakii, and provided a new idea for preventing and inactivating C. sakazakii in PIF.

Key words: tea polyphenols, Cronobacter sakazakii, inactivation, powdered infant formula

\section{INTRODUCTION}

Cronobacter spp. (formerly classified as Enterobacter sakazakii) is an emerging gram-negative, motile, nonspore-forming, rod-shaped, opportunistic foodborne pathogen (Healy et al., 2010; Yan et al., 2012; Sonbol et al., 2013). Although powdered infant formula (PIF) is considered the main source of infection, Cronobacter has been detected in a wide range of environmental

Received June 30, 2015.

Accepted October 3, 2015.

${ }^{1}$ These authors contributed equally to this work.

${ }^{2}$ Corresponding author: yujun_jiang@163.com and food sources (Craven et al., 2010). As a matter of fact, it has been isolated from tea, which is used as a drink for infants $>4$ mo (Chap et al., 2009). Because of ingesting contaminated PIF by Cronobacter strains, the neonates, especially low birthweight individuals, can be infected to suffer from bacteremia, meningitis, and necrotizing enterocolitis, with a high fatality rate of 40 to $80 \%$ (Drudy et al., 2006; Lin and Beuchat, 2007; Holý and Forsythe, 2014). Cronobacter sakazakii had been shown to be the dominant species in Cronobacter spp. isolated from PIF (Forsythe et al., 2014). Similarly, this view was in agreement with the finding of our team by identifying and typing 75 strains of Cronobacter spp. isolated from a wet-mixing PIF manufacturing facility with different methods (Lu et al., 2014). Further, C. sakazakii sequence type (ST) 4 characterized by multi-locus sequence typing was proven to be the predominant sequence type associated with neonatal meningitis (Joseph and Forsythe, 2011). Cronobacter sakazakii ST1 and C. sakazakii ST8 were the main sequence types isolated from PIF and clinical sources, respectively (Joseph et al., 2012a). Meanwhile, C. sakazakii ST64 was found to be one of the dominant sequence types isolated from PIF in China by our team (Fei et al., 2015). Thus, for the C. sakazakii strains with different sequence types, this is an important issue needing further study if differences are present in tolerance to the same antibacterial material. To the best of our knowledge, this is the first report on the tolerance of C. sakazakii associated with its ST.

In recent years, compared with some sterilization techniques and synthetic antibiotics, various natural extracts, including polyphenols and organic acids, have received attention as potential antimicrobials because they are natural and acceptable to consumers. Cranberry pomace extract had been reported to control the growth of Listeria monocytogenes (Vattem et al., 2004). The methanol extract of Lactuca sativa was able to inhibit the growth of various gram-negative and grampositive bacteria with the lowest minimal inhibitory concentration of $2.5 \mathrm{mg} / \mathrm{mL}$ (Edziri et al., 2011). The 
aqueous extract and crude alcohol extract of Mangifera indica seed kernel had significant antimicrobial activity against the isolated pathogen Shigella dysenteriae (Rajan et al., 2011). Furthermore, a variety of studies showed that organic acids could inhibit the growth of Cronobacter strains. Tartaric, citric and malic acid could delay the growth of Cronobacter strains with viable counts of 3.0 to $5.0 \log$ after $24 \mathrm{~h}$ incubation at $\mathrm{pH}$ 5.0, whereas lactic, acetic, butyric, and propionic acid showed an absolute growth inhibition at the same pH (Zhu et al., 2013). To gain further insight into this phenomenon, malic acid, citric acid, and ascorbic acid (VC), as the most common organic acids with increasingly wide application, were selected in our study.

Tea polyphenol (TP) is a significant natural compound extracted from tea, mainly composed of catechins, flavonoids, phenolic acids, and anthocyans, among them, the catechins account for 60 to $80 \%$ (Mukhtar and Ahmad, 2000). It has many beneficial functions to human health, such as antioxidant effect, bacteriostasis, and anticarcinogenic and antiinflammatory activities (Koňariková et al., 2015; Yang and Jiang, 2015). Meanwhile, TP had effective inhibitory effects on mixed biofilm formation of Staphylococcus aureus and Salmonella Enteritidis through inhibiting the bacterial communication signal autoinducer 2 synthesis (Zhang et al., 2014). In addition, it had been reported that TP could effectively inhibit the growth of Serratia marcescens through cell membrane damage, and the inhibition halos increased as the concentration of TP increased within certain limits (Yi et al., 2014). Despite various studies that reported the antimicrobial activity of TP against a variety type of bacteria, the antibacterial mechanism of TP against different bacteria might be different. So far, the literature available on TP inhibiting C. sakazakii was limited, especially in reconstituted PIF.

In our study, we investigated the effect of TP on the 4 C. sakazakii strains with different sequence types isolated from PIF, analyzed the influence of low $\mathrm{pH}$ condition on the bactericidal action of TP, and compared the differences in antimicrobial activity of TP against the C. sakazakii strains with different sequence types.

\section{MATERIALS AND METHODS}

\section{Bacterial Strains}

All the 4 C. sakazakii strains in this study were isolated from PIF in China and identified by multi-locus sequence typing; details of isolates are shown in Table 1. These strains were stored in cryogenic vials at $-20^{\circ} \mathrm{C}$ in the presence of $40 \%$ glycerol as cryoprotectant. To reactivate the C. sakazakii strains, $0.1-\mathrm{mL}$ portions of cultures were inoculated into $10 \mathrm{~mL}$ of Luria-Bertani (LB) broth and cultivated at $37^{\circ} \mathrm{C}$ for $20 \mathrm{~h}$.

\section{Preparation of Unstressed C. sakazakii Cell Suspensions}

After incubation, $2 \mathrm{~mL}$ of each culture was transferred to a sterile Eppendorf tube. Working stationary-phase cell suspensions were collected after centrifugation at $8,000 \times g$ for $10 \mathrm{~min}$, then washed twice with normal saline (NS) at room temperature. The supernatants were discarded and the pellets were re-suspended in 1 $\mathrm{mL}$ of sterile NS. For enumeration, $0.1 \mathrm{~mL}$ of each cell suspension was spread-plated in duplicate on tryptic soy agar (TSA) plates after serial dilution in NS and incubated at $37^{\circ} \mathrm{C}$ for $24 \mathrm{~h}$ to obtain the required concentration of inoculum.

\section{Treatment with TP and Organic Acids in PIF}

A commercial PIF (Wondersun, Harbin, Hei Longjiang Province, China) was purchased and reconstituted according to the manufacturer's instruction. Briefly, 15 $\mathrm{g}$ of the PIF was reconstituted in $100 \mathrm{~mL}$ of sterile distilled water. The rehydrated PIF was pasteurized at $63^{\circ} \mathrm{C}$ for 30 min before use, and no C. sakazakii strains were detected. Based on related studies, an appropriate concentration of $5 \mathrm{mg} / \mathrm{mL}$ was selected as the optimum dosage (Amalaradjou et al., 2009; Joshi et al., 2014). Thus, $5 \mathrm{mg} / \mathrm{mL}$ of TP was added to the rehydrated PIF and shaken gently to make sure it was fully dissolved. Meanwhile, as controls, malic acid, citric acid, and VC were processed in the same way. An Accumet $\mathrm{pH}$ meter (Corning Inc., Corning, NY) was used to determine the $\mathrm{pH}$ of all samples. The initial $\mathrm{pH}$ of rehydrated PIF was $6.8,2$ and the value of $\mathrm{pH}$ decreased to $\mathrm{pH} 3.62$, $3.55,4.55$, and 6.46 after $5 \mathrm{mg} / \mathrm{mL}$ of malic acid, cit-

Table 1. Cronobacter sakazakii strains isolated from powdered infant formula in China

\begin{tabular}{lccc}
\hline $\begin{array}{l}\text { C. sakazakii } \\
\text { strain }\end{array}$ & $\mathrm{ID}^{1}$ & $\mathrm{ST}^{2}$ & $\mathrm{CC}^{3}$ \\
\hline CE21 & 858 & 1 & 1 \\
CE1 & 872 & 4 & 4 \\
CE13 & 890 & 8 & 8 \\
CE25 & 905 & 64 & 64 \\
\hline
\end{tabular}

${ }^{1} \mathrm{ID}=$ strain identification code in the pubMLST.org/cronobacter database (http://www.pubmlst.org/cronobacter).

${ }^{2} \mathrm{ST}=$ sequence types.

${ }^{3} \mathrm{CC}=$ clonal complex defined as clusters of sequence types with single locus variants, as given by Joseph et al. (2012b). 
Table 2. Results of the final $\mathrm{pH}$ after $7 \mathrm{~h}$ treatment and turbidity measurements ${ }^{1}$

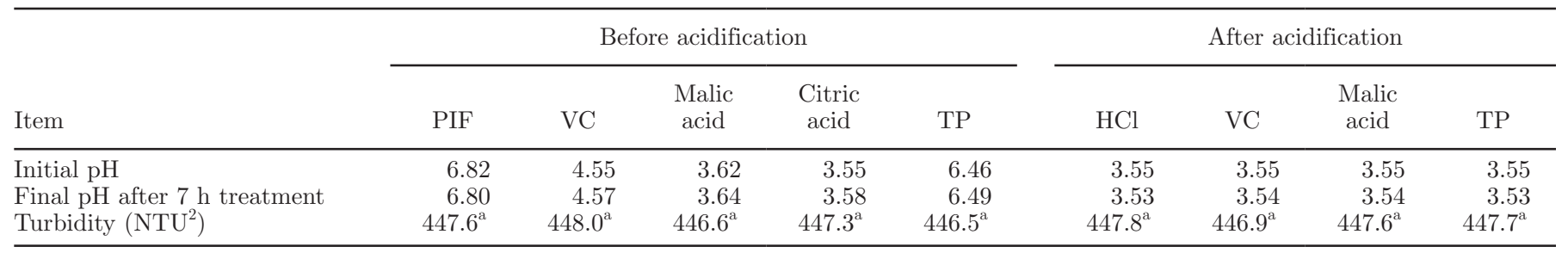

${ }^{a}$ Turbidity measurements did not differ between treatments.

${ }^{1} \mathrm{PIF}=$ powdered infant formula; $\mathrm{VC}=$ ascorbic acid; $\mathrm{TP}=$ tea polyphenols.

${ }^{2} \mathrm{NTU}=$ nephelometric turbidity units.

ric acid, $\mathrm{VC}$, and $\mathrm{TP}$, respectively, were added (Table 2 ). One hundred microliters of cell suspension of the 4 C. sakazakii strains was separately added to $10 \mathrm{~mL}$ of rehydrated PIF with different treatments to obtain a final desired concentration of approximately $7.0 \mathrm{log}$ $\mathrm{cfu} / \mathrm{mL}$. The PIF inoculated with C. sakazakii strains but without treatment was used as a control. The cell suspensions with different treatments were incubated at $37^{\circ} \mathrm{C}$ for $1,3,5$, and $7 \mathrm{~h}$. Then, at each time point, 0.1-mL portions of appropriately diluted cultures were spread-plated on TSA in duplicate and incubated at $37^{\circ} \mathrm{C}$ for $24 \mathrm{~h}$ to enumerate the surviving populations of the pathogen. The final $\mathrm{pH}$ values of differently treated media were measured after $7 \mathrm{~h}$ of treatment.

\section{Treatment with Inorganic Acids in PIF}

To investigate the role played by the $\mathrm{pH}$ of different treatments in C. sakazakii reduction, the $\mathrm{pH}$ of all samples was adjusted to 3.55 (the lowest $\mathrm{pH}$ value of the aforementioned samples) with $4 \mathrm{M} \mathrm{HCl}$. The $\mathrm{HCl}$-treated PIF of $\mathrm{pH} 3.55$ was used for comparison purposes. The following inoculation, cultivation, and enumeration processes were performed in accordance with the above description.

\section{Turbidity Measurements}

The addition of organic acids and acidification with $\mathrm{HCl}$ in PIF could reduce the $\mathrm{pH}$ of treated media, and the acidic environment might affect the colloidal stability of casein micelles (Post et al., 2012). To approximate changes in casein micelles, solution turbidity as a measure of protein-protein aggregation was monitored by the transmittance at $450 \mathrm{~nm}$ using a Shimadzu 1601 PC UV-visible spectrometer as described by Madadlou et al. (2009). In brief, a 3-mL portion of the treated medium was poured into a 1-cm-pathlength cuvette and placed into the cuvette holder. All the aforementioned treatments in nonacidified and acidified PIF containing
$5 \mathrm{mg} / \mathrm{mL}$ of malic acid, citric acid, $\mathrm{VC}$, and $\mathrm{TP}$ were measured.

\section{Treatments with TP in NS}

To avoid the influence of proteins in PIF on antibacterial effect of TP (Staszewski et al., 2011), the study was conducted in sterile NS. Accordingly, $5 \mathrm{mg} / \mathrm{mL}$ of $\mathrm{TP}$ was added to the sterile $\mathrm{NS}$, the initial $\mathrm{pH}$ of the samples were all 6.93, which decreased to $\mathrm{pH} 3.44$ after mixing with $5 \mathrm{mg} / \mathrm{mL}$ of TP. The following inoculation, cultivation, and enumeration processes were performed in accordance with the above description.

\section{Recovery of the Stressed C. sakazakii Cells}

According to the previous report, after treatment with $5 \mathrm{mg} / \mathrm{mL}$ of acidified TP for $7 \mathrm{~h}$ in nutritious rehydrated PIF, the 4 C. sakazakii strains were transferred to fresh LB broth and PIF immediately, and then incubated at $37^{\circ} \mathrm{C}$ for $6 \mathrm{~h}$ and $12 \mathrm{~h}$ to estimate bactericidal or bacteriostatic effects (Joshi et al., 2014). Moreover, the 4 C. sakazakii strains treated with $5 \mathrm{mg} / \mathrm{mL}$ of TP in NS for $1 \mathrm{~h}$ were also observed in the same way. The counts of $C$. sakazakii strains were determined by plating $0.1 \mathrm{~mL}$ of appropriate diluents on TSA plates and incubating the plates at $37^{\circ} \mathrm{C}$ for $24 \mathrm{~h}$. Besides, considering the unfavorable environmental conditions, microorganisms might exist in a state known as viable but nonculturable. Cox et al. (2015) reported that these nonculturable cells could not be recovered by various cultivation methods. So this form of C. sakazakii cells did not affect the results because it could not be determined under the current experimental conditions.

\section{Transmission Electron Microscopy Analysis}

To eliminate the influence of proteins in PIF on the observation of cell morphology (Karlsson et al., 2007), the treatments with TP in NS for $1 \mathrm{~h}$ were prepared 
and the treatments in LB broth for $1 \mathrm{~h}$ served as controls. All the 4 C. sakazakii strains treated with $5 \mathrm{mg} /$ $\mathrm{mL}$ of TP in NS or without TP in LB broth were drawn after $1 \mathrm{~h}$ of contact time and centrifuged at 3,000 $\times g$ for $5 \mathrm{~min}$ at room temperature. To fix the cells, the pellets were resuspended in $0.1 M$ sodium phosphate buffer ( $\mathrm{pH} 7.1$ ) containing 3\% glutaraldehyde solution. Cronobacter sakazakii cells were washed twice with the same buffer after fixation for $12 \mathrm{~h}$, and then $1 \%$ osmium tetraoxide was used to fix the cells for $6 \mathrm{~h}$ at $25^{\circ} \mathrm{C}$, and washed 3 times with the same buffer. The cells were dehydrated with a graded series of ethanol (50, 70, 90, and 100\%) for 10 min, and embedded in Epon Lx-112 (Ladd Research, Williston, VT) after washing with acetone. Thin sections were cut with a knife on a Power Tome XL microtome (Boeckeler Instruments, Tucson, AZ) and double-stained with uranyl acetate and lead citrate. Samples were examined in a transmission electron microscope (Hitachi, Tokyo, Japan). Micrographs were digitally recorded.

\section{Statistical Analysis}

Each treatment was carried out with 3 replications. Statistical analysis was calculated by ANOVA with the SPSS 20.0 software (SPSS Inc., Chicago, IL). Tukey's multiple range test was used to determine the significant differences $(P<0.05)$ between treatments.

\section{RESULTS}

\section{Reduction of C. sakazakii in PIF Treated with TP}

After $7 \mathrm{~h}$ treatment, the final $\mathrm{pH}$ of samples containing $5 \mathrm{mg} / \mathrm{mL}$ malic acid, citric acid, $\mathrm{VC}$ and $\mathrm{TP}$ were $3.64,3.58,4.57$, and 6.49 , respectively (Table 2 ). As a result, the $\mathrm{pH}$ values of different treatments were almost stable after $7 \mathrm{~h}$, which had less than 0.1 unit alteration to the initial $\mathrm{pH}$. The growth of C. sakazakii strains treated with $5 \mathrm{mg} / \mathrm{mL}$ of TP in PIF (pH 6.46) was significantly inhibited $(P<0.05)$ compared with C. sakazakii strains growing in PIF ( $\mathrm{pH}$ 6.82; Figure 1). As controls, $5 \mathrm{mg} / \mathrm{mL}$ of malic acid ( $\mathrm{pH} 3.62)$, citric acid $(\mathrm{pH} 3.55)$, and $\mathrm{VC}(\mathrm{pH} 4.55)$ were also found to significantly reduce $(P<0.05) C$. sakazakii strains in PIF. The order of inhibition of different treatments was citric acid $(\mathrm{pH} 3.55)>$ malic acid $(\mathrm{pH} 3.62)>\mathrm{VC}(\mathrm{pH}$ 4.55) > TP (pH 6.46) > PIF (pH 6.82).

\section{Reduction of C. sakazakii in PIF Treated with Acidified TP}

Table 2 shows that the final $\mathrm{pH}$ of all samples were almost stable after $7 \mathrm{~h}$ of treatment. The inhibition effect of TP acidified with $\mathrm{HCl}$ against $C$. sakazakii was obviously stronger $(P<0.05)$ than the effect of control groups (Figure 2). Further, none of the 4 C. sakazakii strains treated with $5 \mathrm{mg} / \mathrm{mL}$ of TP acidified with $\mathrm{HCl}$ in PIF ( $\mathrm{pH} 3.55$ ) could be detected on TSA after $7 \mathrm{~h}$ of treatment. The inhibition effect of $\mathrm{HCl}$ as an inorganic acid against $C$. sakazakii was greater $(P<0.05)$ than the effect of citric acid and malic acid.

\section{Turbidity Analysis}

The hydration level of the casein micelles could be influenced by $\mathrm{pH}$, temperature, and pressure, which might bring about the changes of casein in particle size, aggregation, and gelation (Orlien et al., 2010). The results of solution turbidity were illustrated in Table 2 . As shown in Table 2, the turbidity remained relatively stable $(P>0.05)$ after the addition of organic acids and acidification with $\mathrm{HCl}$ in $\mathrm{PIF}$, which indicated that acid-treated PIF did not lead to casein aggregation and precipitation.

\section{Reduction of C. sakazakii in NS Treated with TP}

In NS, TP showed strong antimicrobial properties against $C$. sakazakii and resulted in a complete elimination of the organism. As a consequence, no C. sakazakii strains could be detected on TSA after $1 \mathrm{~h}$ treatment with $5 \mathrm{mg} / \mathrm{mL}$ of TP in NS (data not shown).

\section{Antimicrobial Ability of TP and Acidified TP Against C. sakazakii with Different ST}

The differences in antimicrobial ability of TP and acidified TP with $\mathrm{HCl}$ against $C$. sakazakii strains with different ST, including ST1, ST4, ST8, and ST64, are shown in Figure 3. The results revealed that the survival rates of the 4 C. sakazakii strains with different ST were different in rehydrated PIF with $5 \mathrm{mg} / \mathrm{mL}$ of nonacidified and acidified TP. In treatments with nonacidified TP in PIF, from 1 to $3 \mathrm{~h}$, the surviving bacterial counts of $C$. sakazakii CE1 (ST4) were significantly higher $(P<0.05)$ than those of the other 3 C. sakazakii strains with ST1, ST8, and ST64. On the contrary, the surviving bacterial counts of C. sakazakii CE25 (ST64) were the lowest among the 4 C. sakazakii strains. From 5 to $7 \mathrm{~h}$, significant differences $(P<0.05)$ were found in survival rates among the 4 C. sakazakii strains with different ST, and the order of survival rates was $C$. sakazakii $\mathrm{CE} 1(\mathrm{ST} 4)>$ C. sakazakii $\mathrm{CE} 21(\mathrm{ST} 1)>C$. sakazakii CE13 (ST8) > C. sakazakii CE25 (ST64). In treatments with $\mathrm{TP}$ acidified with $\mathrm{HCl}$ in $\mathrm{PIF}$, after 


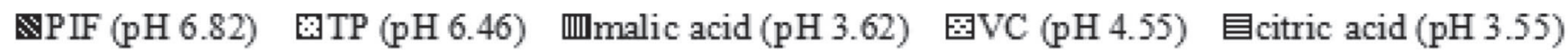
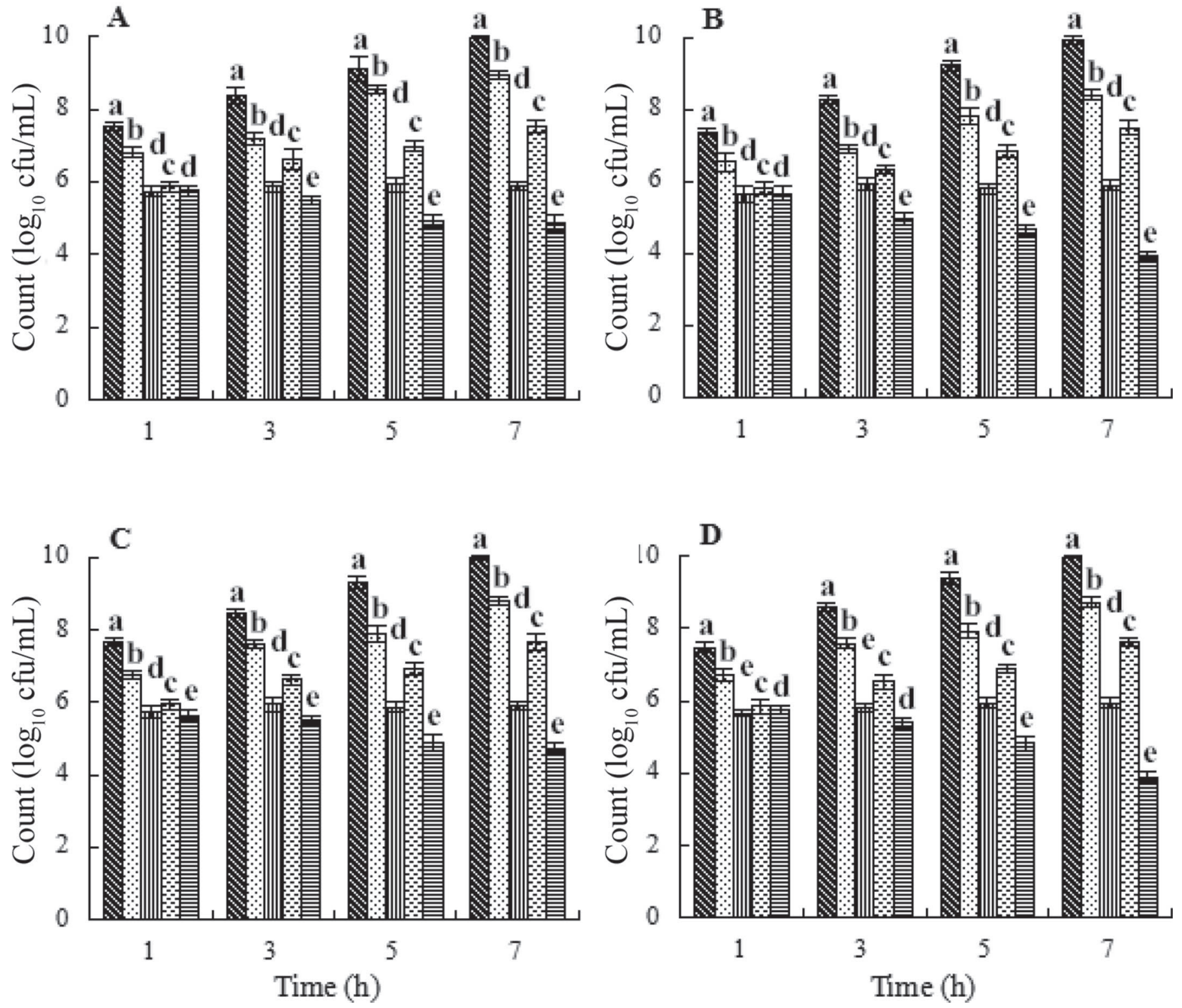

Figure 1. Effect of $5 \mathrm{mg} / \mathrm{mL}$ of tea polyphenols (TP) against Cronobacter sakazakii CE1 (A), CE25 (B), CE13 (C), and CE21 (D) in rehydrated powdered infant formula (PIF) at $37^{\circ} \mathrm{C}$; the rehydrated PIF and $5 \mathrm{mg} / \mathrm{mL}$ of malic acid, citric acid, and ascorbic acid (VC) serve as controls. Error bars represent standard deviation. Different letters (a-e) represent significant differences between treatments within the same time points $(P<0.05)$.

$1 \mathrm{~h}$, the antimicrobial effects of acidified TP against C. sakazakii CE1 (ST4) and C. sakazakii CE13 (ST8) were significantly stronger $(P<0.05)$ than the effects against $C$. sakazakii CE21 (ST1) and C. sakazakii CE25 (ST64). From 3 to $5 \mathrm{~h}$, the antimicrobial ability of acidified TP against $C$. sakazakii strains showed significant differences $(P<0.05)$, and the order of survival rates was C. sakazakii $\mathrm{CE} 1$ (ST4) $>$ C. sakazakii $\mathrm{CE} 13$
(ST8) > C. sakazakii CE21 $(\mathrm{ST} 1)>$ C. sakazakii $\mathrm{CE} 25$ (ST64). After $7 \mathrm{~h}$, all 4 C. sakazakii strains were reduced to undetectable levels.

\section{Recovery of the Stressed C. sakazakii Cells}

The 4 C. sakazakii strains with different ST following treatment with $5 \mathrm{mg} / \mathrm{mL}$ of $\mathrm{TP}$ acidified with $\mathrm{HCl}$ in 
$\mathbb{N P I F}(\mathrm{pH} 6.82)$

目 $\mathrm{HCl}(\mathrm{pH} 3.55)$
Ormalic acid ( $\mathrm{pH} 3.55)$

国VC (pH 3.55) 目酸itric acid (pH 3.55)

⿴囗十 $(\mathrm{pH} 3.55)$
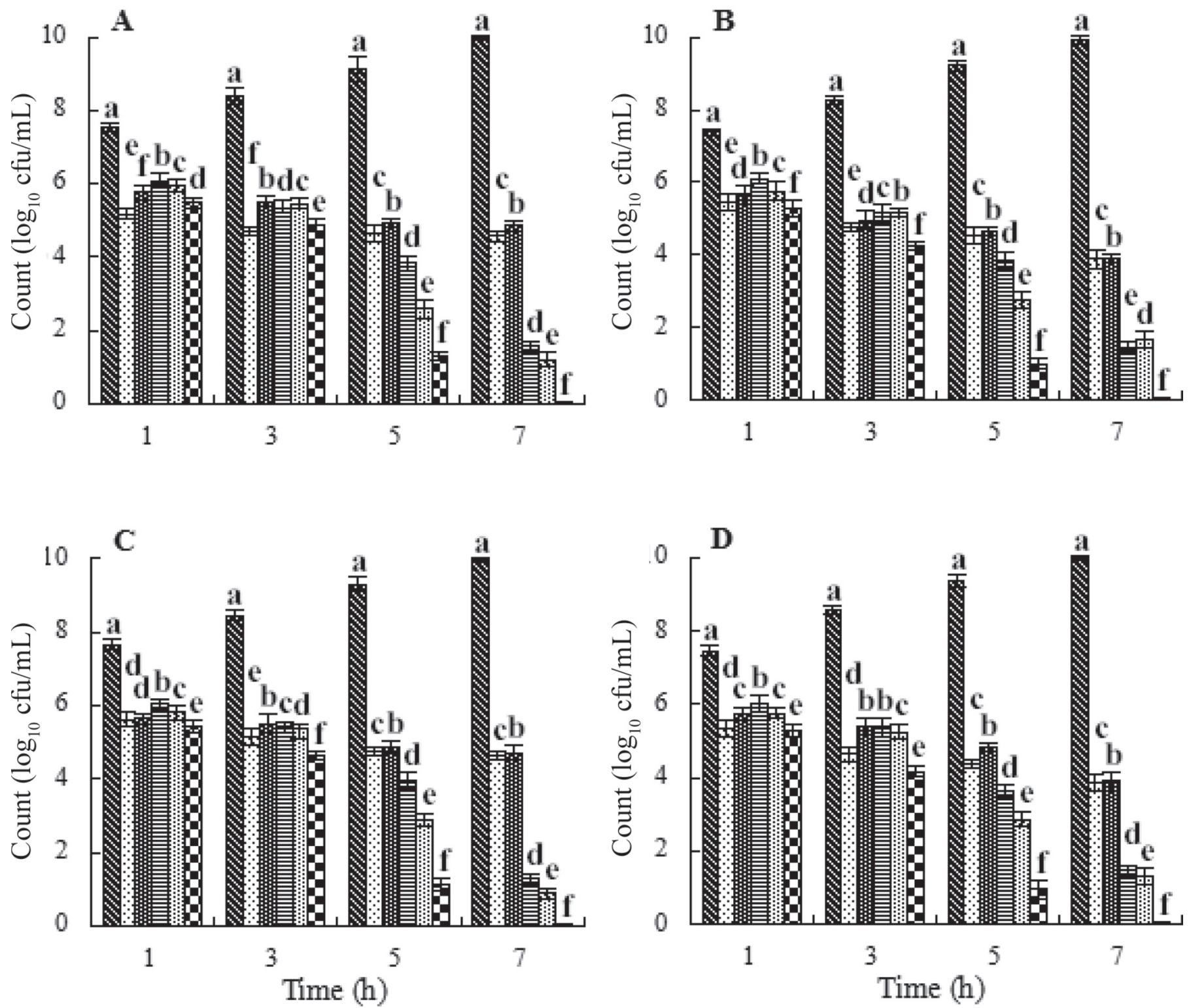

Figure 2. Effect of $5 \mathrm{mg} / \mathrm{mL}$ of tea polyphenols (TP), malic acid, and ascorbic acid (VC) acidified with $4 M \mathrm{HCl}$ in rehydrated powdered infant formula (PIF) against Cronobacter sakazakii CE1 (A), CE25 (B), CE13 (C), and CE21 (D) at $37^{\circ} \mathrm{C}$. Error bars represent standard deviation. Different letters $(\mathrm{a}-\mathrm{f})$ represent significant differences between treatments within the same time points $(P<0.05)$.

PIF for $7 \mathrm{~h}$ showed no growth after 6 and $12 \mathrm{~h}$ incubation in fresh recovery (LB broth and PIF) medium. Consistently, no C. sakazakii cells were able to restore growth in LB broth or in PIF after treatment with 5 $\mathrm{mg} / \mathrm{mL}$ of $\mathrm{TP}$ in NS for $1 \mathrm{~h}$. It should be apparent from these results that the action of TP against C. sakazakii was a bactericidal rather than bacteriostatic process.

\section{Transmission Electron Microscope Analysis Results}

The 4 C. sakazakii strains with different ST treated with $5 \mathrm{mg} / \mathrm{mL}$ of TP in NS or without TP in LB broth for $1 \mathrm{~h}$ were examined by transmission electron microscopy. The transmission electron microscopy images (Figure 4) showed that, compared with controls, the 
图 C. sakazakii CE1 (ST4)

目 C. sakazakii CE13 (ST8)

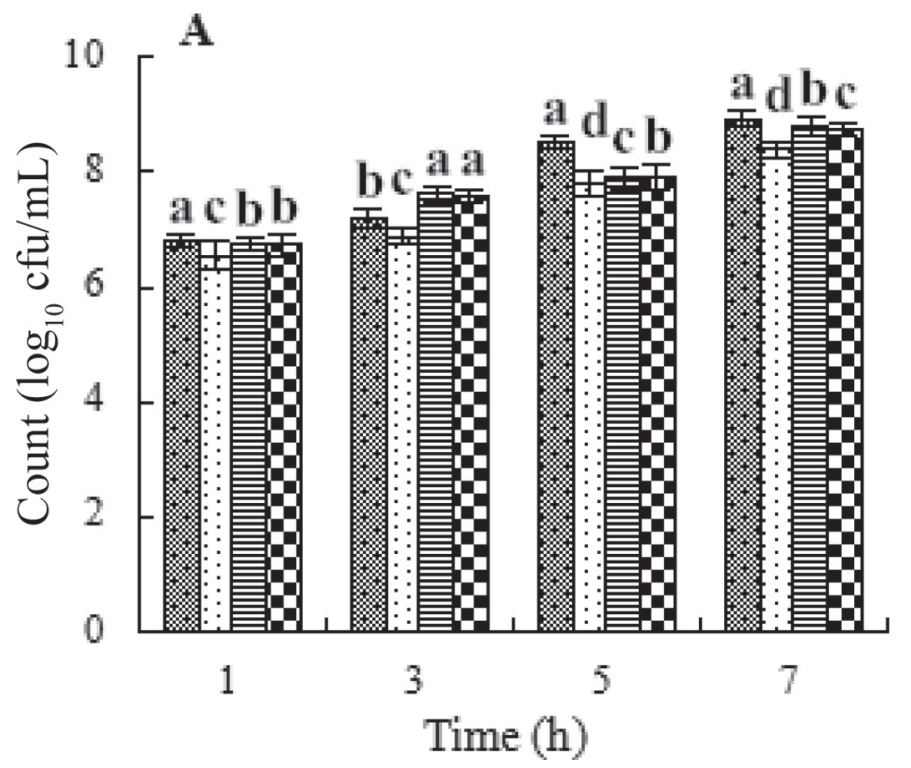

C. sakazakii CE25 (ST64)

C. sakazatii CE21 (ST1)

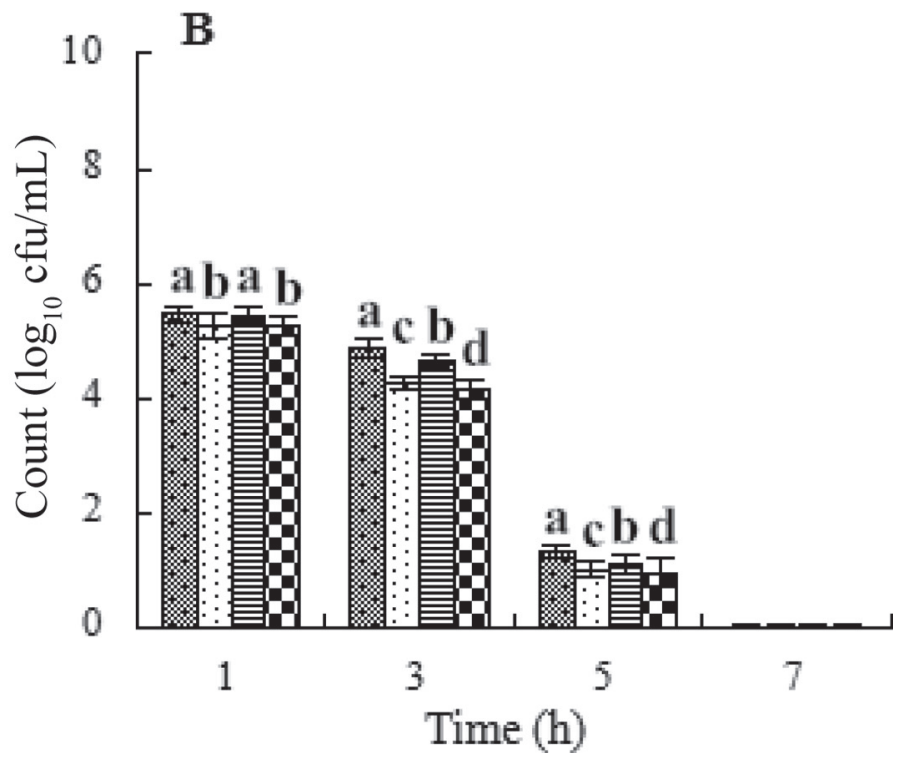

Figure 3. (A) Effect of $5 \mathrm{mg} / \mathrm{mL}$ of tea polyphenols (TP) in rehydrated powdered infant formula (PIF) against Cronobacter sakazakii CE1 (ST4), CE25 (ST64), CE13 (ST8), and CE21 (ST1) at $37^{\circ} \mathrm{C}$. (B) Effect of $5 \mathrm{mg} / \mathrm{mL}$ of TP acidified with $4 M$ HCl in rehydrated PIF against $C$. sakazakii strains CE1 (ST4), CE25 (ST64), CE13 (ST8), CE21 (ST1) at 37 ${ }^{\circ}$. Error bars represent standard deviation. Different letters (a-d) represent significant differences between the 4 C. sakazakii strains with different sequence type $(\mathrm{ST})$ within the same time points $(P<0.05)$.

cell morphology of all C. sakazakii strains with different ST treated with TP was seriously damaged, and the cytoplasm leaked out.

\section{DISCUSSION}

Natural extracts with antioxidant capacity such as organic acids and phenolics could effectively inhibit the growth of foodborne pathogens (Kim et al., 2009, 2012; Zhu et al., 2013). Kim et al. (2009) showed that hot water-soluble muscadine seed extracts in total phenolics $(2.78 \mathrm{mg} / \mathrm{mL})$, malic acid $(1.87 \mathrm{mg} / \mathrm{mL})$, and tannic acid $(7.1 \mathrm{mg} / \mathrm{mL})$ were able to inactivate $6.0 \log \mathrm{cfu} / \mathrm{mL}$ C. sakazakii strains within $1 \mathrm{~h}$ at $37^{\circ} \mathrm{C}$, and the various organic acids as the main active ingredients played an important role in C. sakazakii reduction. Besides, $0.5 \%$ trans-cinnamaldehyde could reduce $C$. sakazakii strains to undetectable levels from $7.0 \mathrm{log} \mathrm{cfu} / \mathrm{mL}$ within 4 $\mathrm{h}$ at $37^{\circ} \mathrm{C}$ or $23^{\circ} \mathrm{C}$ (Amalaradjou et al., 2009). In our study, all the experiments were carried out at $37^{\circ} \mathrm{C}$ because it was near the optimum growth temperature of C. sakazakii (Iversen and Forsythe, 2003; Chenu and Cox, 2009). At this temperature, C. sakazakii strains had higher metabolic, growth, and death rates, which could help to better investigate the antimicrobial ef- fect of TP. Indeed, a population of $7.0 \mathrm{log} \mathrm{cfu} / \mathrm{mL} C$. sakazakii was completely killed after treatment with 5 $\mathrm{mg} / \mathrm{mL}$ of TP in NS (pH 3.44) for $1 \mathrm{~h}$ at $37^{\circ} \mathrm{C}$. Further, $7.0 \log \mathrm{cfu} / \mathrm{mL}$ C. sakazakii strains could be reduced to undetectable levels after $7 \mathrm{~h}$ treatment in rehydrated PIF supplemented with $5 \mathrm{mg} / \mathrm{mL}$ of TP acidified with $\mathrm{HCl}(\mathrm{pH} 3.55)$ at $37^{\circ} \mathrm{C}$. These results suggested that the antimicrobial effect of TP against $C$. sakazakii strains was satisfactory and acceptable.

The $\mathrm{pH}$ played an important role in the action of natural extracts against C. sakazakii. The antimicrobial effect of citric acid, malic acid, and VC was enhanced after acidification. This phenomenon was due to the synergistic counteractions, $\mathrm{H}^{+}$dissociated from $\mathrm{HCl}$ could increase the accumulation in the undissociated organic acids, thus its effective concentration was altered (Zhu et al., 2013). Some studies found that organic acids due to undissociated form and higher pKa could easily penetrate the bacterial cell membrane to reduce intracellular $\mathrm{pH}$ of bacteria, further causing disturbance and damage of enzymatic reaction and the nutrient transport system; ultimately, the irreversible denaturation of acid-labile protein and DNA led to the death of cells (Alvarez-Ordonez et al., 2014). However, $\mathrm{TP}$ at $\mathrm{pH} 3.55$ led to a reduction of about $7.0 \mathrm{log} \mathrm{cfu} /$ 
A

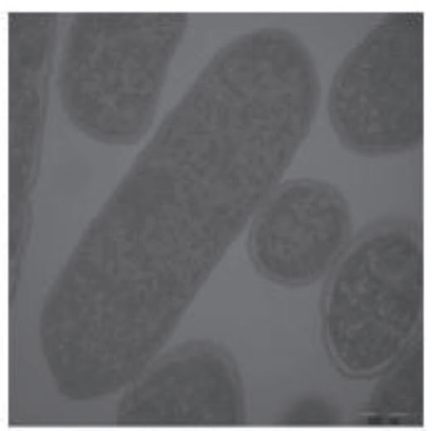

$-500 \mathrm{~nm}-$

CE1 (ST4)

B

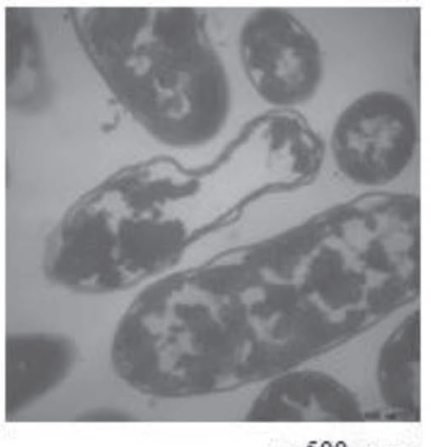

$-500 \mathrm{~nm}-$

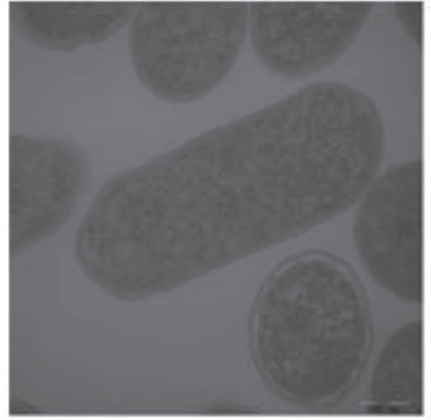

$-500 \mathrm{~nm}-$ CE25 (ST64)

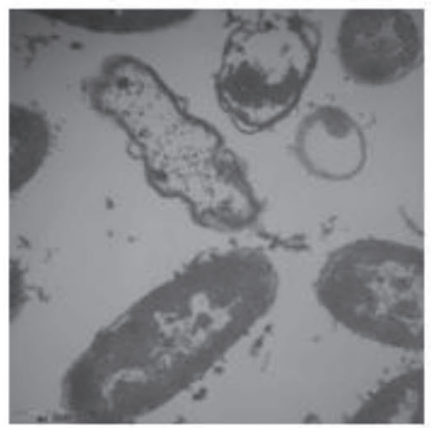

$-500 \mathrm{~nm}-$
CE25 (ST64)

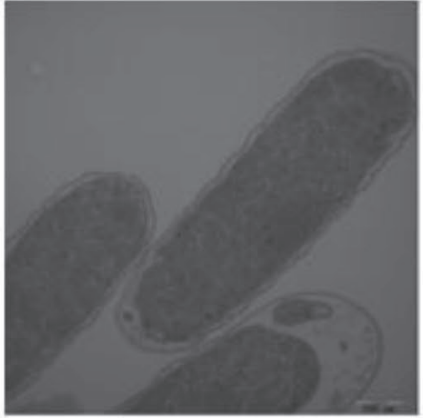

$-500 \mathrm{~nm}-$

CE13 (ST8)

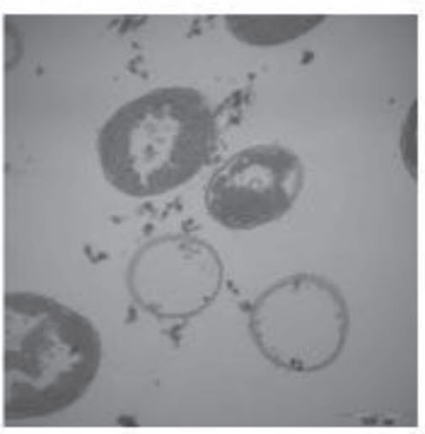

$-500 \mathrm{~nm}-$

CE13 (ST8)

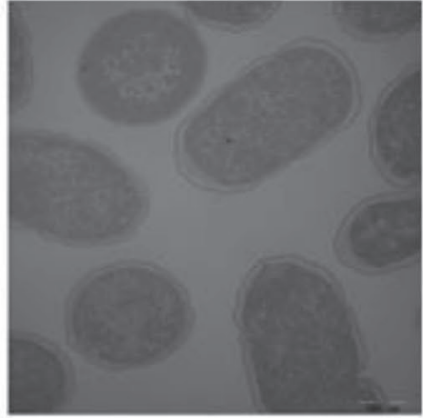

$-500 \mathrm{~nm}-$

CE21 (ST1)

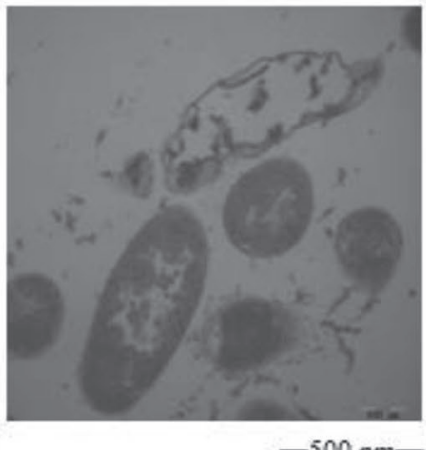

$-500 \mathrm{~nm}-$

CE21 (ST1)

Figure 4. (A) Transmission electron microscopy images of the 4 Cronobacter sakazakii strains treated with Luria-Bertani broth at $37^{\circ} \mathrm{C}$ for $1 \mathrm{~h}$. (B) Transmission electron microscopy images of the 4 C. sakazakii strains treated with $5 \mathrm{mg} / \mathrm{mL}$ of tea polyphenols (TP) in normal saline at $37^{\circ} \mathrm{C}$ for $1 \mathrm{~h} . \mathrm{ST}=$ sequence type.

$\mathrm{mL}$ after $7 \mathrm{~h}$ treatment in PIF, which was greater than that caused by citric acid, malic acid, and VC. According to the previous reports, polyphenols and proteins were able to combine to form protein-polyphenol complexes, which could significantly influence their biological activities (Richard et al., 2006; Staszewski et al., 2011), but catechins, as the most abundant and biologically active compounds in TP, were very stable in acidic solutions ( $\mathrm{pH}<4$; Chen et al., 2001). So a low $\mathrm{pH}$ condition could inhibit the formation of proteinpolyphenol complexes and improve the biological activity of TP to have a more efficient bactericidal action.

Moreover, in contrast with the complexation and degradation reactions of polyphenols in the nutrientrich media of rehydrated PIF, TP in NS showed a noticeable inhibitory activity against the $C$. sakazakii strains and caused the same reduction of the tested strains within $1 \mathrm{~h}$. Additionally, compared the $\mathrm{pH}$ value between the different TP treatments, in NS ( $\mathrm{pH} 3.44$ ) and in rehydrated PIF ( $\mathrm{pH}$ 6.46), PIF could improve the initial $\mathrm{pH}$ of media from $\mathrm{pH} 3.44$ to 6.46. Similarly, the buffered effect of PIF also appeared in the study by Zhu et al. (2013). Therefore, the appropriate acidification of PIF was necessary to play a satisfactory antimicrobial effect of TP against C. sakazakii strains in PIF. As indicated earlier, the addition of organic acids and appropriate acidification with $\mathrm{HCl}$ did not result in the quality deterioration of PIF. The acidified TP could be used as a disinfectant to sterilize the air and the surface of equipment and floor that coated with milk powder particles in the dairy factory. As a preliminary study, this article lays the foundation for further research. Further in-depth studies about practical applicability of TP need to be pursued, and data in this study will be very useful.

The antibacterial mechanism of TP had been preliminary revealed, but the exact mechanism of action was not clear. However, in this study, the permeability of the outer and inner membrane of C. sakazakii dramatically increased after TP treatment, which caused severe disruption of cell membrane, followed by the release of cytoplasm. In contrast, C. sakazakii strains treated with 
blueberry proanthocyanidins and blueberry juice were reduced because of cell clustered together along with the formation of blebs and viewing pores, and blueberry phenolics was considered to disturb cell membrane fluidity, change fatty acid profile, and destroy cellular metabolism (Joshi et al., 2014). Therefore, bactericidal effect of TP on C. sakazakii was an irreversible process compared with the bacteriostatic action of blueberry proanthocyanidins and blueberry juice. Furthermore, the antibacterial mechanism of TP was a complicated process, and a wide variety of reasonable explanations was reported. Navarro-Martínez et al. (2006) found that TP pigallocatechin-3-gallate inhibited ergosterol synthesis by disturbing folic acid metabolism in Candida albicans. Cho et al. (2008) demonstrated that TP could differentially stimulate the expression of various proteins in the bacteria and synergize the bactericidal activity of oxacillin for methicillin-resistant Staphylococcus aureus. Therefore, a more comprehensive study on the mechanism of TP against $C$. sakazakii should be performed as soon as possible. However, undoubtedly, as a potential natural antibiotic, TP was a good choice because of its efficiency and irreversible bactericidal action.

Cronobacter spp. is a diverse genus in the Enterobacteriaceae family. In this study, we researched the antibacterial effect of TP against the 4 C. sakazakii strains with different sequence types isolated from PIF, including ST4, ST1, ST8, and ST64, and found $5 \mathrm{mg} / \mathrm{mL}$ of TP could effectively kill $7.0 \log \mathrm{cfu} / \mathrm{mL}$ the above 4 C. sakazakii strains in NS (pH 3.44) and in acidified PIF (pH 3.55) after 1 and $7 \mathrm{~h}$ of treatment, respectively. However, in the middle phase of treatment, namely from 3 to $5 \mathrm{~h}$, the antibacterial effect of TP on the 4 C. sakazakii strains with different ST showed significant differences $(P<0.05)$. The reduction of $C$. sakazakii CE1 (ST4) was the lowest among the $4 C$. sakazakii strains CE1 (ST4), CE21 (ST1), CE13 (ST8), and CE25 (ST64). Interestingly, Joseph et al. (2012b) applied the 7-loci method to Cronobacter spp. isolates obtained between 1950 and 2009 and showed that $C$. sakazakii sequence type 4 was the predominant ST associated with severe cases of neonatal meningitis. This result suggested that the dominant position of $C$. sakazakii CE1 (ST4) in Cronobacter genus might be due to its stronger tolerance ability. But this inference needs to be further confirmed, because C. sakazakii CE1 (ST4) cannot represent all the C. sakazakii ST4 strains.

\section{CONCLUSIONS}

The effective bactericidal ability of TP against $C$. sakazakii is a meaningful finding and provides a new option for preventing and killing C. sakazakii stains using natural extracts. Irreversible cytochylema leakage improves the chance that TP becomes an efficient natural antibiotic. However, to use TP as a food additive to prevent Cronobacter contamination in PIF, it is critical that the TP dosage is optimized and that safety experiments in infants are conducted.

\section{ACKNOWLEDGMENTS}

This study was supported by the National Key Technology Support Program (2013BAD18B11, 2012BAD29B07), the Science Foundation for Distinguished Young Scholars of Heilongjiang Province (JC201415), the National Natural Science Foundation of China (31171718), the National Science and Technology Project (2011AA100902), and the Promotion Program for Innovation of Scientific Research in Heilongjiang Province (YC13D005).

\section{REFERENCES}

Alvarez-Ordonez, A., C. Cummins, T. Deasy, T. Clifford, M. Begley, and C. Hill. 2014. Acid stress management by Cronobacter sakazakii. Int. J. Food Microbiol. 178:21-28.

Amalaradjou, M. A. R., T. A. Hoagland, and K. Venkitanarayanan. 2009. Inactivation of Enterobacter sakazakii in reconstituted infant formula by trans-cinnamaldehyde. Int. J. Food Microbiol. 129:146-149.

Chap, J., P. Jackson, R. Siqueira, N. Gaspar, C. Quintas, J. Park, T. Osaili, R. Shaker, Z. Jaradat, S. H. Hartantyo, N. Abdullah Sani, S. Estuningsih, and S. J. Forsythe. 2009. International survey of Cronobacter sakazakii and other Cronobacter spp. in follow up formulas and infant foods. Int. J. Food Microbiol. 136:185-188.

Chen, Z. Y., Q. Y. Zhu, D. Tsang, and Y. Huang. 2001. Degradation of green tea catechins in tea drinks. J. Agric. Food Chem. 49:477-482.

Chenu, J. W., and J. M. Cox. 2009. Cronobacter ('Enterobacter sakazakii'): current status and future prospects. Lett. Appl. Microbiol. 49:153-159.

Cho, Y.-S., N. L. Schiller, and K.-H. Oh. 2008. Antibacterial effects of green tea polyphenols on clinical isolates of methicillin-resistant Staphylococcus aureus. Curr. Microbiol. 57:542-546.

Cox, N. A., L. J. Richardson, and M. A. Harrison. 2015. Efficiency of several cultural methods and a chick bioassay to recover drystressed Campylobacter. J. Food Saf. 35:91-101.

Craven, H. M., C. M. McAuley, L. L. Duffy, and N. Fegan. 2010. Distribution, prevalence and persistence of Cronobacter (Enterobacter sakazakii) in the nonprocessing and processing environments of five milk powder factories. J. Appl. Microbiol. 109:1044-1052.

Drudy, D., N. R. Mullane, T. Quinn, P. G. Wall, and S. Fanning. 2006. Enterobacter sakazakii: An emerging pathogen in powdered infant formula. Clin. Infect. Dis. 42:996-1002.

Edziri, H. L., M. A. Smach, S. Ammar, M. A. Mahjoub, Z. Mighri, M. Aouni, and M. Mastouri. 2011. Antioxidant, antibacterial, and antiviral effects of Lactuca sativa extracts. Ind. Crops Prod. 34:1182-1185.

Fei, P., C. X. Man, B. B. Lou, S. J. Forsythe, Y. L. Chai, R. Li, J. T Niu, and Y. J. Jiang. 2015. Genotyping and source tracking of the Cronobacter sakazakii and C. malonaticus isolated from powdered infant formula and an infant formula production factory in China. Appl. Environ. Microbiol. 81:5430-5439.

Forsythe, S. J., B. Dickins, and K. A. Jolley. 2014. Cronobacter, the emergent bacterial pathogen Enterobacter sakazakii comes of age; MLST and whole genome sequence analysis. BMC Genomics $15: 1121$. 
Healy, B., S. Cooney, S. O'Brien, C. Iversen, P. Whyte, J. Nally, J. J. Callanan, and S. Fanning. 2010. Cronobacter (Enterobacter sakazakii): An opportunistic foodborne pathogen. Foodborne Pathog. Dis. 7:339-350.

Holý, O., and S. Forsythe. 2014. Cronobacter spp. as emerging causes of healthcare-associated infection. J. Hosp. Infect. 86:169-177.

Iversen, C., and S. J. Forsythe. 2003. Risk profile of Enterobacter sakazakii, an emergent pathogen associated with infant milk formula. Trends Food Sci. Technol. 14:443-454.

Joseph, S., P. Desai, Y. Ji, C. A. Cummings, R. Shih, L. Degoricija, A. Rico, P. Brzoska, S. E. Hamby, N. Masood, S. Hariri, H. Sonbol, N. Chuzhanova, M. McClelland, M. R. Furtado, and S. J. Forsythe. 2012a. Comparative analysis of genome sequences covering the seven Cronobacter species. PLoS ONE 7:e49455.

Joseph, S., and S. J. Forsythe. 2011. Predominance of Cronobacter sakazakii sequence type 4 in neonatal infections. Emerg. Infect. Dis. 17:1713-1715.

Joseph, S., H. Sonbol, S. Hariri, P. Desai, M. McClelland, and S. J. Forsythe. 2012b. Diversity of the Cronobacter genus as revealed by multilocus sequence typing. J. Clin. Microbiol. 50:3031-3039.

Joshi, S. S., A. B. Howell, and D. H. D'Souza. 2014. Cronobacter sakazakii reduction by blueberry proanthocyanidins. Food Microbiol. $39: 127-131$.

Karlsson, A. O., R. Ipsen, and Y. Ardö. 2007. Observations of casein micelles in skim milk concentrate by transmission electron microscopy. Lebenson. Wiss. Technol. 40:1102-1107.

Kim, S.-J., Y.-M. Bae, and S.-Y. Lee. 2012. Stress response of acidshocked Cronobacter sakazakii against subsequent acidic $\mathrm{pH}$, mild heat, and organic acids. Food Sci. Biotechnol. 21:205-210.

Kim, T. J., J. L. Silva, W. L. Weng, W. W. Chen, M. Corbitt, Y. S. Jung, and Y. S. Chen. 2009. Inactivation of Enterobacter sakazakii by water-soluble muscadine seed extracts. Int. J. Food Microbiol. 129:295-299.

Koňariková, K., M. Jezovicova, J. Kerestes, H. Gbelcova, Z. Durackova, and I. Zitnanova. 2015. Anticancer effect of black tea extract in human cancer cell lines. Springerplus 4:127.

Lin, L.-C., and L. R. Beuchat. 2007. Survival of Enterobacter sakazakii in infant cereal as affected by composition, water activity, and temperature. Food Microbiol. 24:767-777.

Lu, Y., Y. Chen, X. A. Lu, J. Lv, C. X. Man, Y. L. Chai, and Y. J. Jiang. 2014. Comparison of methods for the microbiological identification and typing of Cronobacter species in infant formula. J. Dairy Sci. 97:632-641.

Madadlou, A., M. E. Mousavi, Z. Emam-djomeh, M. Ehsani, and D. Sheehan. 2009. Sonodisruption of re-assembled casein micelles at different $\mathrm{pH}$ values. Ultrason. Sonochem. 16:644-648.

Mukhtar, H., and N. Ahmad. 2000. Tea polyphenols: Prevention of cancer and optimizing health. Am. J. Clin. Nutr. 71:1698S-1702S.

Navarro-Martínez, M. D., F. Garcia-Canovas, and J. N. RodriguezLopez. 2006. Tea polyphenol epigallocatechin-3-gallate inhibits er- gosterol synthesis by disturbing folic acid metabolism in Candida albicans. J. Antimicrob. Chemother. 57:1083-1092.

Orlien, V., L. Boserup, and K. Olsen. 2010. Casein micelle dissociation in skim milk during high-pressure treatment: Effects of pressure, pH, and temperature. J. Dairy Sci. 93:12-18.

Post, A. E., B. Arnold, J. Weiss, and J. Hinrichs. 2012. Effect of temperature and $\mathrm{pH}$ on the solubility of caseins: Environmental influences on the dissociation of alpha(S)- and beta-casein. J. Dairy Sci. 95:1603-1616.

Rajan, S., T. Thirunalasundari, and S. Jeeva. 2011. Anti-enteric bacterial activity and phytochemical analysis of the seed kernel extract of Mangifera indica Linnaeus against Shigella dysenteriae (Shiga, corrig.) Castellani and Chalmers. Asian Pac. J. Trop. Med. 4:294300.

Richard, T., D. Lefeuvrec, A. Descenditb, S. Quideauc, and J. P. Monti. 2006. Recognition characters in peptide-polyphenol complex formation. Biochim. Biophys. Acta 1760:951-958.

Sonbol, H., S. Joseph, C. M. McAuley, H. M. Craven, and S. J. Forsythe. 2013. Multilocus sequence typing of Cronobacter spp. from powdered infant formula and milk powder production factories. Int. Dairy J. 30:1-7.

Staszewski, M. V., A. M. R. Pilosof, and R. J. Jagus. 2011. Antioxidant and antimicrobial performance of different Argentinean green tea varieties as affected by whey proteins. Food Chem. 125:186-192.

Vattem, D. A., Y.-T. Lin, R. G. Labbe, and K. Shetty. 2004. Phenolic antioxidant mobilization in cranberry pomace by solid-state bioprocessing using food grade fungus Lentinus edodes and effect on antimicrobial activity against select food borne pathogens. Innov. Food Sci. Emerg. Technol. 5:81-91.

Yan, Q. Q., O. Condell, K. Power, F. Butler, B. D. Tall, and S. Fanning. 2012. Cronobacter species (formerly known as Enterobacter sakazakii) in powdered infant formula: A review of our current understanding of the biology of this bacterium. J. Appl. Microbiol. 113:1-15.

Yang, X., and X. Jiang. 2015. Antifungal activity and mechanism of tea polyphenols against Rhizopus stolonifer. Biotechnol. Lett. 37:1463-1472.

Yi, S., W. Wang, F. Bai, J. Zhu, J. Li, X. Li, Y. Xu, T. Sun, and Y. He. 2014. Antimicrobial effect and membrane-active mechanism of tea polyphenols against Serratia marcescens. World J. Microbiol. Biotechnol. 30:451-460.

Zhang, H., W. Zhou, W. Zhang, A. Yang, Y. Liu, Y. Jiang, S. Huang, and J. Su. 2014. Inhibitory effects of citral, cinnamaldehyde, and tea polyphenols on mixed biofilm formation by foodborne Staphylococcus aureus and Salmonella Enteritidis. J. Food Prot. 77:927933.

Zhu, S., S. Schnell, and M. Fischer. 2013. Growth inhibition of Cronobacter spp. strains in reconstituted powdered infant formula acidified with organic acids supported by natural stomach acidity. Food Microbiol. 35:121-128. 